\title{
Micropatterning Transmission Electron Microscopy Grids to Direct Cell Positioning within Whole-Cell Cryo-Electron Tomography Workflows
}

\author{
Bryan S. Sibert ${ }^{*}, 1,2,3$, Joseph Y. Kim ${ }^{*}{ }^{1,4}$, Jie E. Yang ${ }^{1,2,3}$, Elizabeth R. Wright ${ }^{1,2,3,5}$ \\ ${ }^{1}$ Department of Biochemistry, University of Wisconsin, Madison ${ }^{2}$ Cryo-Electron Microscopy Research Center, Department of Biochemistry, University \\ of Wisconsin, Madison ${ }^{3}$ Midwest Center for Cryo-Electron Tomography, Department of Biochemistry, University of Wisconsin, Madison ${ }^{4}$ Department of \\ Chemistry, University of Wisconsin, Madison ${ }^{5}$ Morgridge Institute for Research
}

*These authors contributed equally

\section{Corresponding Author}

Elizabeth R. Wright

erwright2@wisc.edu

\section{Citation}

Sibert, B.S., Kim, J.Y., Yang, J.E.,

Wright, E.R. Micropatterning

Transmission Electron Microscopy Grids to Direct Cell Positioning within Whole-Cell Cryo-Electron Tomography Workflows. J. Vis. Exp. (175), e62992, doi:10.3791/62992 (2021).

\section{Date Published}

September 13, 2021

DOI

$10.3791 / 62992$

URL

jove.com/video/62992

\section{Abstract}

Whole-cell cryo-electron tomography (cryo-ET) is a powerful technology that is used to produce nanometer-level resolution structures of macromolecules present in the cellular context and preserved in a near-native frozen-hydrated state. However, there are challenges associated with culturing and/or adhering cells onto TEM grids in a manner that is suitable for tomography while retaining the cells in their physiological state. Here, a detailed step-by-step protocol is presented on the use of micropatterning to direct and promote eukaryotic cell growth on TEM grids. During micropatterning, cell growth is directed by depositing extra-cellular matrix (ECM) proteins within specified patterns and positions on the foil of the TEM grid while the other areas remain coated with an anti-fouling layer. Flexibility in the choice of surface coating and pattern design makes micropatterning broadly applicable for a wide range of cell types. Micropatterning is useful for studies of structures within individual cells as well as more complex experimental systems such as host-pathogen interactions or differentiated multi-cellular communities. Micropatterning may also be integrated into many downstream whole-cell cryo-ET workflows, including correlative light and electron microscopy (cryo-CLEM) and focused-ion beam milling (cryo-FIB).

\section{Introduction}

With the development, expansion, and versatility of cryoelectron microscopy (cryo-EM), researchers have examined a wide range of biological samples in a near-native state from macromolecular $(\sim 1 \mathrm{~nm})$ to high $(\sim 2 \AA)$ resolution. Single-particle cryo-EM and electron diffraction techniques are best applied to purified macromolecules in solution or in a crystalline state, respectively ${ }^{1,2}$. Whereas cryo-electron tomography (cryo-ET) is uniquely suited for near-native structural and ultrastructural studies of large, heterologous objects such as bacteria, pleomorphic viruses, and eukaryotic 
cells $^{3}$. In cryo-ET, three-dimensional (3D) information is obtained by physically tilting the sample on the microscope stage and acquiring a series of images through the sample at different angles. These images, or tilt-series, often cover a range of $+60 /-60$ degrees in one-to-three-degree increments. The tilt-series can then be computationally reconstructed into a 3D volume, also known as a tomogram ${ }^{4}$.

All cryo-EM techniques require the sample to be embedded in a thin layer of amorphous, non-crystalline, vitreous ice. One of the most commonly used cryo-fixation techniques is plunge freezing, where the sample is applied to the EM grid, blotted, and rapidly plunged into liquid ethane or a mixture of liquid ethane and propane. This technique is sufficient for the vitrification of samples from $<100 \mathrm{~nm}$ to $\sim 10 \mu \mathrm{m}$ in thickness, including cultured human cells, such as HeLa cells $^{5,6}$. Thicker samples, such as mini-organoids or tissue biopsies, up to $200 \mu \mathrm{m}$ in thickness, can be vitrified by high-pressure freezing ${ }^{7}$. However, due to increased electron scattering of thicker samples, sample and ice thickness for cryo-ET is limited to $\sim 0.5-1 \mu \mathrm{m}$ in $300 \mathrm{kV}$ transmission electron microscopes. Therefore, whole-cell cryo-ET of many eukaryotic cells is limited to the cell periphery or extensions of cells unless additional sample preparation steps are used, such as cryo-sectioning $^{8}$ or focused-ion beam milling $^{9,10,11}$.

A limitation of many whole-cell cryo-ET imaging experiments is data collection throughput ${ }^{12}$. Unlike single-particle cryo$E M$, where thousands of isolated particles can often be imaged from a single TEM grid square, cells are large, spread-out, and must be grown at low enough density to allow for the cells to be preserved in a thin layer of vitreous ice. Often the region of interest is limited to a particular feature or sub-area of the cell. Further limiting throughput is the propensity of cells to grow on areas that are not amenable for TEM imaging, such as on or near TEM grid bars. Due to unpredictable factors associated with cell culture on TEM grids, technological developments are needed to improve sample accessibility and throughput for data acquisition.

Substrate micropatterning with adherent extra-cellular matrix (ECM) proteins is a well-established technique for live-cell light microscopy to direct the growth of cells on rigid, durable, and optically transparent surfaces such as glass and other tissue culture substrates ${ }^{13,14}$. Micropatterning has also been performed on soft and/or three-dimensional (3D) surfaces. Such techniques have not only allowed for the precise positioning of cells; they have also supported the creation of multicellular networks, such as patterned neural cell circuits $^{15}$. Bringing micropatterning to cryo-ET will not only increase throughput, but it can also open up new studies for exploring complex and dynamic cellular microenvironments.

Recently, several groups have begun using micropatterning techniques on TEM grids through multiple approaches ${ }^{16,17}$. Here, the use of a maskless photopatterning technique for TEM grids is described using the Alvéole PRIMO micropatterning system, which features high-resolution and contactless patterning. With this micropatterning system, an anti-fouling layer is applied on the top of the substrate, followed by the application of a photocatalyst and ablation of the anti-fouling layer in user-defined patterns with a UV laser. ECM proteins can then be added to the patterns for the appropriate cell culture. This method has been used by several groups for cryo-ET studies of retinal pigment epithelial-1 (RPE1), Madin-Darby canine kidney-II (MDCKII), human foreskin fibroblast (HFF), and endothelial cell lines ${ }^{16,17,18}$. This micropatterning system is compatible with multiple anti-fouling layer substrates as well as either a liquid or gel photocatalyst reagent. A variety of ECM proteins 
can be selected from and adapted for the specificity of the cell line, conferring versatility for the user.

Micropatterning has been successfully applied to a number of projects within the laboratory ${ }^{19}$. Here, a micropatterning protocol is presented, including specific adaptations to study cultured HeLa cells, respiratory syncytial virus (RSV)-infected BEAS-2B cells, and primary larval Drosophila melanogaster neurons ${ }^{20}$.

\section{Protocol}

The protocol described here is a compilation of the cell culture, micropatterning, and imaging methods used by the Wright lab and the Cryo-EM Research Center at the University of Wisconsin, Madison. The workflow is presented in Figure 1. Additional training and instructional materials are available at the following sites: https://cryoem.wisc.edu or https://wrightlab.wisc.edu

\section{Preparation of grids for patterning}

1. Transfer the TEM grids onto a clean glass slide, carbon side up (the standard thickness of the carbon foil is 12 $\mathrm{nm})$. Using a carbon evaporator, ACE600, evaporate 5-8 $\mathrm{nm}$ of additional carbon onto the grids to increase overall carbon film durability.

NOTE: This step is not necessary for $\mathrm{SiO}_{2}$ grids. This step may also be done in advance; store the coated grids in a low humidity environment such as a vacuum desiccator.

2. Transfer the grids to a grid prep holder and glow discharge the grids carbon side up. Using a glow discharge system, glow discharge the grids for $60 \mathrm{~s}$ at $10 \mathrm{~mA}$ with an $80 \mathrm{~mm}$ working distance and vacuum pressure of $1.0 \times 10^{-3}$ mbar. Do this within $15-30 \mathrm{~min}$ of the next step.

NOTE: Grid prep holders can be commercially bought or homemade with a piece of filter paper on a small Petri dish.

\section{Application of the anti-fouling layer}

NOTE: Proper sterile technique should be used when handling the grids, and all solutions should be sterile and/or filter sterilized.

1. Transfer the grids (carbon side up) to a clean glass slide or coverslip with at least $1 \mathrm{~cm}$ of separation between the grids. Pipette $10 \mu \mathrm{L}$ of $0.05 \%$ poly-L-lysine (PLL) onto each grid. Incubate the grids in a humid chamber, such as an enclosed plastic box with moist paper towels, for at least $30 \mathrm{~min}$.

NOTE: This step can be extended to overnight. Be sure the humidity level in the chamber is sufficient to prevent the grids from drying out.

2. Wash each grid three times with $15 \mu \mathrm{L}$ of $0.1 \mathrm{M}$ HEPES $\mathrm{pH}$ 8.5. For each wash, remove most of the liquid from the grid with a pipette without letting the grid dry. Add 15 $\mu L$ of fresh buffer, incubate for at least $30 \mathrm{~s}$ and repeat. Leave each grid in $15 \mu \mathrm{L}$ of $0.1 \mathrm{M}$ HEPES after the final wash.

NOTE: In this step and future steps, it is important to keep the grid wet and to avoid contact between the pipette and the grid.

3. Prepare $10 \mu \mathrm{L}$ of $100 \mathrm{mg} / \mathrm{mL}$ polyethylene glycolsuccinimidyl valerate (PEG-SVA) in 0.1 M HEPES pH 8.5 for each grid. The PEG-SVA will dissolve quickly with gentle mixing resulting in a clear solution. 
NOTE: Do not prepare the PEG-SVA solution in advance. PEG-SVA has a half-life of $10 \mathrm{~min}$ at $\mathrm{pH}$ 8.5. Avoid exposing the PEG-SVA stock to excessive moisture by storing it in a desiccator or dry environment at $-20^{\circ} \mathrm{C}$ and warming to room temperature before opening.

4. Immediately after preparing the PEG-SVA solution, remove the $15 \mu \mathrm{L}$ drop of HEPES $\mathrm{pH} 8.5$ from each grid (taking care not to dry the grid) and add a $10 \mu \mathrm{L}$ drop of the PEG-SVA solution. Incubate the grids in a humid chamber for at least $1 \mathrm{~h}$.

NOTE: This step can be extended to overnight. Be sure the humidity in the chamber is sufficient to prevent the grids from drying out.

5. Wash each grid three times with $15 \mu \mathrm{L}$ of sterile water. For each wash, remove most of the liquid from the grid with a pipette without letting the grid dry, add $15 \mu \mathrm{L}$ of fresh water, incubate for at least $30 \mathrm{~s}$ and repeat. Leave each grid in $15 \mu \mathrm{L}$ of water after the final wash.

\section{Applying PLPP gel}

1. Prepare a clean microscope coverslip for each grid. Complete the following steps for each grid, one grid at a time, to minimize the chance of the grid drying out.

2. Place a $1.0 \mu \mathrm{L}$ drop of water on the center of the coverslip to help with placing the grid on the coverslip and keeping the grid wet. Carefully transfer the grid from the $15 \mu \mathrm{L}$ water drop to the $1.0 \mu \mathrm{L}$ water drop on the coverslip. Be sure to place the grid carbon side up.

3. Carefully place a polydimethylsiloxane (PDMS) stencil over the grid, taking care to keep the grid centered and to minimize stencil contact with the carbon foil of the grid.
4. Add $1.0 \mu \mathrm{L}$ of 4-benzoylbenzyl-trimethylammonium chloride (PLPP) gel onto the grid. Pipette gently to mix (do not touch the grid with the pipette tip).

5. Move the coverslip with the grid to a dark location to dry. The gel will dry in approximately 15-30 min.

\section{Calibration and design of the micropattern}

1. Color one side of a glass coverslip with a highlighter. Add black lines from a fine-tipped permanent marker to make focusing easier. Place the coverslip on the microscope such that the colored side faces the objective lens. Using brightfield mode, focus on the highlighter.

2. Ensure the microscope and the micropatterning system is powered on, and the correct light path is set. Open Micromanager and the Leonardo software (Plugins > Leonardo) on the microscope computer.

3. Select calibrate and follow the on-screen instructions. Adjust the microscope focus so that the image projected onto the slide is in focus. The exposure time may need to be decreased. After calibration, select Pattern Now.

4. Record the micrometer/pixel $(\mu \mathrm{m} / \mathrm{px})$ ratio reported under calibration data in the top left window of the program (Figure 2, area 1). Use this ratio to determine the number of pixels to use per micrometer when designing a pattern.

5. After calibration, ensure that the software is now open with a live brightfield view from the microscope. Load a prepared grid on a coverslip (section 3 ) onto the stage with the grid facing the objective lens. Position the stage and adjust the focus so that the grid is visible in the software window.

6. Measure the size of the grid squares and grid bars in micrometers. The software includes a ruler activated by the button near the bottom left corner to measure the 
grid (Figure 2, area 2). For example, the patterns used here for a 200 mesh grid correspond to $\sim 87 \times 87 \mu \mathrm{m}$ grid squares and $\sim 36 \mu \mathrm{m}$ grid bars.

NOTE: The software offers flexibility in resizing patterns on the fly, so minor inaccuracies in measurement can be tolerated.

7. Based on the measurements and ratios above, create pattern(s) with any image creation software. The minimum feature size with a $20 \times$ objective is $1.2 \mu \mathrm{m}$. Patterns should be saved as uncompressed 8-bit .tiff files.

1. Ensure the software does not rescale images to a different pixel size when saving. The pattern should fit within an $800 \times 800$ pixel box, sufficient to cover four grid squares.

NOTE: Pixels with a value of 255 (white) will be patterned at the highest intensity (total dose of the laser) and pixels with a value of zero (black) will not be patterned. Any pixels with an intermediate value will be patterned with a dose of approximately $(\mathrm{X} / 255)^{\star}$ total dose. In Figure 3A, pixel values of 255 and 129 were used for the greyscale patterns. Once the pattern is designed it can be saved and reused without modification.

\section{Micropatterning}

1. After calibration, ensure that the software is now open with a live brightfield view from the microscope. Load a prepared grid on a coverslip (section 3 ) onto the stage with the grid facing the objective lens. Position the stage and adjust the focus to see the grid in the software.

2. For an initial run, design a new template. In the software, select Add ROI (not shown, in the location of Figure 2 area 3) and choose a 3,000 $\mu \mathrm{m}$ circle. Position the circle ROI over the grid using the brightfield image on the screen as a guide. Press lock to secure the ROI.

3. After locking the ROI in place, select Add Pattern (not shown, in the location of Figure 2 area 3). Choose the pattern designed in section 4. Divide the grid into six regions to allow independent focusing and positioning in each region to factor for uneven grids. An $8 \times 8$ grid square region for each corner of the grid and a $2 \times 8$ grid square region on each side of the center, leaving the center four grid squares unpatterned (Figure 2, center image).

4. Use the replication options (Figure 2, area 4) to generate copies of the initial pattern to reach the desired number of total copies of the pattern. Adjust the spacing between copies to match the spacing between grid squares if necessary.

5. Set the Total Dose for the pattern. $30 \mathrm{~mJ} / \mathrm{mm}^{2}$ is a good starting point. See the discussion section for more details.

6. Under Expert Options (Figure 2, area 4) adjust the angle of the region to match that of the grid squares. Regions can be repositioned using the mouse. The ratio (size) of the patterns can also be adjusted. Iterate through adjusting the angle, position, space between, and ratio of the pattern until the patterns line up with the grid squares. Move the microscope stage to change the region of the grid in the live brightfield display.

7. Press Lock to save the changes made to the region.

8. To copy a region, click the Duplicate button (Figure 2, area 5, two sheets of paper icon) next to its name in the Actions panel on the left. To reposition, rename, or edit the copy, click on its name in the Action panel. 
9. Repeat steps 5.4-5.9 as necessary to fill all of the desired regions.

10. Once the complete template is designed and positioned, Save the template file within the software (Figure 2, area 6 , bar with up arrow icon in top toolbar).

11. When loading a previously saved template (bar with down arrow icon) center the ROI over the grid and press Lock. Click on each region in the Action Panel to change the angle, position, dose, and/or pattern file.

12. Once the template and patterns are positioned, uncheck all but one of the regions in the Action Panel in the software.

13. Use the microscope stage to navigate to that region and focus on the carbon foil. Clicking the Eyeball icon in the Action panel (Figure 2, area 5) will toggle the display of the pattern overlay on or off.

14. Once the grid is in focus, close the brightfield shutter and press the Play icon in the bottom right corner of the software to begin the patterning process, which can be monitored live.

15. In the action panel, select the box for the next region. Open the brightfield shutter so that the grid is visible and center that region using the microscope stage. Repeat steps 5.13-5.14 for each region in the Action Panel.

16. Remove the coverslip with the grid from the microscope, and immediately pipette $10 \mu \mathrm{L}$ of sterile phosphatebuffered saline (PBS) onto the grid.

17. After $10 \mathrm{~min}$, remove the stencil with tweezers, then wash the grid $3 x$ with $15 \mu \mathrm{L}$ of PBS. After the final wash, place each grid in $15 \mu \mathrm{L}$ of PBS and move the grids to a dark location.

\section{Deposition of ECM proteins}

1. For cultured cells, follow steps 6.2-6.5; for primary Drosophila neurons, follow steps 6.6-6.10.

2. Prepare at least $15 \mu \mathrm{L}$ of $\mathrm{ECM}$ for each grid. For BEAS-2B cells, prepare a final concentration of 0.01 $\mathrm{mg} / \mathrm{mL}$ bovine fibronectin and $0.01 \mathrm{mg} / \mathrm{mL}$ fluorophoreconjugated fibrinogen in sterile PBS. For HeLa cells, prepare $0.01 \mathrm{mg} / \mathrm{mL}$ bovine collagen I and $0.1 \mathrm{mg} / \mathrm{mL}$ fluorophore-conjugated fibrinogen in sterile PBS.

3. Remove most of the PBS from each grid and apply 15 $\mu \mathrm{L}$ of the ECM. Incubate the grid in a humid chamber at room temperature for at least $1 \mathrm{~h}$.

NOTE: This step may be extended to overnight at $4{ }^{\circ} \mathrm{C}$.

4. After incubation in ECM, wash each grid $5 x$ with sterile PBS. For each wash, remove most of the liquid with a pipette without letting the grid dry, add $15 \mu \mathrm{L}$ of fresh PBS, incubate for at least $30 \mathrm{~s}$, and repeat. Leave each grid in PBS after the final wash.

NOTE: Grids can be stored for up to a week in PBS at 4 ${ }^{\circ} \mathrm{C}$ with no observed deterioration in quality.

5. Use a fluorescence microscope to detect the fluorophore in the ECM to confirm patterning and that the carbon foil remained intact. A few broken squares are generally tolerable.

6. For primary Drosophila neurons, move the patterned grids to a $30 \mathrm{~mm}$ glass bottom dish containing sterile PBS.

7. Aspirate the PBS from the dish and apply $2 \mathrm{~mL}$ of 0.5 $\mathrm{mg} / \mathrm{mL}$ fluorophore-conjugated concanavalin A. Incubate overnight at $25^{\circ} \mathrm{C}$ in a sterile environment. 
8. Remove the concanavalin A solution from the dish (without drying the grids) and wash the grids $3 x$ with PBS. For each wash, add and remove $2 \mathrm{~mL}$ PBS from the dish.

9. Use a fluorescence microscope to detect the fluorophore in the ECM to confirm patterning and that the carbon foil remained intact. A few broken squares are generally tolerable.

10. After the final wash, remove the PBS from the glass bottom dish and add $2 \mathrm{~mL}$ of freshly-prepared, sterilefiltered supplemented Schneider's Drosophila media ${ }^{21}$, containing $20 \%$ heat-inactivated fetal bovine serum (FBS), $5 \mu \mathrm{g} / \mathrm{mL}$ insulin, $100 \mu \mathrm{g} / \mathrm{mL}$ penicillin, $100 \mu \mathrm{g} / \mathrm{mL}$ streptomycin, and $10 \mu \mathrm{g} / \mathrm{mL}$ tetracycline. Incubate at 25 ${ }^{\circ} \mathrm{C}$ in a sterile environment until the neurons are ready to be plated.

\section{Preparation of primary Drosophila cells prior to seeding}

1. Sterilize a $55 \mathrm{~mm}$ dissection dish with $70 \% \mathrm{EtOH}$, and then add to the dish $2-3 \mathrm{~mL}$ of sterile-filtered $1 \times$ dissection saline (9.9 mM HEPES pH 7.5, $137 \mathrm{mM} \mathrm{NaCl}$, $5.4 \mathrm{mM} \mathrm{KCl}, 0.17 \mathrm{mM} \mathrm{NaH}_{2} \mathrm{PO}_{4}, 0.22 \mathrm{mM} \mathrm{KH}_{2} \mathrm{PO}_{4}, 3.3$ $\mathrm{mM}$ glucose, $43.8 \mathrm{mM}$ sucrose $)^{21}$.

2. Pick $30-403^{\text {rd }}$ instar larvae gently from the food using a pair of tweezers.

3. Place the larvae into the tube with $1 \times$ PBS, then transfer them into the second tube with $1 \times$ PBS to wash the larvae.

4. Transfer the larvae into the tube with $70 \% \mathrm{EtOH}$ to wash off the PBS, then transfer them into the second tube with $70 \% \mathrm{EtOH}$. Leave the larvae in the second tube for $2-3$ min to sterilize the larvae.
5. Transfer the larvae into a tube with $1 \times$ dissection saline, then immediately transfer them into the second tube with $1 \times$ dissection saline.

6. Transfer individual larvae onto the dissecting dish containing $1 \times$ dissection saline. With a pair of forceps and a dissection microscope, quickly tear each larvae to extract the brain and transfer it to the third tube with $1 x$ dissection saline. Repeat until all brains are extracted.

7. Centrifuge the tube containing the brains at $300 \times g$ for $1 \mathrm{~min}$.

8. Discard the supernatant, and wash with $1 \mathrm{~mL}$ of $1 \times$ dissection saline and centrifuge the tube at $300 \times \mathrm{g}$ for 1 min. Repeat this step one more time.

9. Discard the supernatant until $200-250 \mu \mathrm{L}$ is left in the tube and add $20 \mu \mathrm{L}$ of $2.5 \mathrm{mg} / \mathrm{mL}$ Liberase in $1 \mathrm{x}$ dissection saline.

10. Rotate the tube on a rotator for $1 \mathrm{~h}$ at room temperature; during this hour, pipette the solution 25-30 times every 10 $\min$. By the end, the solution should be slightly opaque.

11. Centrifuge the cells at $300 \times g$ for $5 \mathrm{~min}$.

12. Discard the supernatant, then add $1 \mathrm{~mL}$ of supplemented Schneider's media. Pipette the solution 30 times to mix.

13. Centrifuge the cells at $300 \times g$ for $5 \mathrm{~min}$.

14. Discard the supernatant and wash the cell pellet by adding $1 \mathrm{~mL}$ of supplemented Schneider's media. Pipette the solution 30 times to mix.

15. Centrifuge the cells at $300 \times g$ for $5 \mathrm{~min}$.

16. Discard the supernatant, then resuspend the cell pellet with $300 \mu \mathrm{L}$ of supplemented Schneider's media. Pipette the solution $30-40$ times to mix. 


\section{Culture and RSV infection of BEAS-2B and HeLa cells}

1. Maintain HeLa cells and BEAS-2B cells in T75 flasks at $37{ }^{\circ} \mathrm{C}$ and $5 \% \mathrm{CO}_{2}$. Passage cells every $3-4$ days once reaching approximately $80 \%$ confluency. Maintain HeLa cells in DMEM $+10 \%$ FBS $+1 \times$ Antibiotic-Antimycotic. Maintain BEAS-2B in RPMI + 10\% FBS + 1× AntibioticAntimycotic $6,22,23$.

2. For seeding of uninfected cells, skip to section 9 . BEAS-2B and HeLa cells are susceptible to RSV infection; BEAS-2B cells were used for all experiments involving RSV shown here.

NOTE: Perform all BSL-2 steps in compliance with institutional protocols using an appropriate biosafety cabinet (BSC) and personal protective equipment (PPE).

3. Prior to RSV infection of cells, passage $5 \times 10^{4}$ cells per well into a 6-well plate (surface area $\sim 9.6 \mathrm{~cm}^{2}$ ) with $2 \mathrm{~mL}$ of growth media and incubate overnight.

4. Trypsinize and count one well of cells. To trypsinize, aspirate media from one well and wash with $2 \mathrm{~mL}$ of sterile PBS without $\mathrm{Mg}^{2+}$ and $\mathrm{Ca}^{2+}$ to remove residual media. Add $500 \mu \mathrm{L}$ of $0.25 \%$ trypsin solution. Incubate at $37^{\circ} \mathrm{C}$ for $5-10 \mathrm{~min}$. Periodically check the cells to see if they are released from the surface. Once the cells are released, add $1.5 \mathrm{~mL}$ of culture media.

5. Mix $100 \mu \mathrm{L}$ of trypsinized cells with $100 \mu \mathrm{L}$ of trypan blue. Pipette $10 \mu \mathrm{L}$ of diluted cell mix into a hemocytometer. Count the cells and calculate the number of cells per well. Use this number to calculate $\mathrm{MOI}$ below.

6. Prepare a dilution of RSV-A2mK $+{ }^{24}$ in growth media to achieve an MOI of 10 per-well in $750 \mu \mathrm{L}$ of media. The $\mathrm{MOI}$ of RSV-A2mK+ can be calculated from fluorescent focus units (FFU) titers of the stock (For example: for 1.0 $\times 10^{5}$ cells per well and an RSV stock of $1.0 \times 10^{8} \mathrm{FFU} /$ $\mathrm{mL}$, dilute the viral stock $1: 75$ to $1 \times 10^{6} \mathrm{FFU} / 750 \mu \mathrm{L}$ or $\left.1.33 \times 10^{6} \mathrm{FFU} / \mathrm{mL}\right)$.

7. Aspirate the media from the cells in the 6-well dish and add $750 \mu \mathrm{L}$ of the viral solution from above to each well.

8. Rock the plate at room temperature for $1 \mathrm{~h}$.

9. After $1 \mathrm{~h}$, bring the total volume per well up to $2 \mathrm{~mL}$ with growth media pre-warmed to $37^{\circ} \mathrm{C}$ and place the plate in an incubator set to $37^{\circ} \mathrm{C}$ with $5 \% \mathrm{CO}_{2}$ for $6 \mathrm{~h}$.

10. Trypsinize the cells to release them and proceed to seeding as described below. After seeding, incubate the grids for an additional $18 \mathrm{~h}$ before plunge freezing (for a total $24 \mathrm{~h}$ post-infection).

\section{Cell seeding onto micropatterned grids}

1. For cultured cells, follow steps 9.2-9.8; for primary Drosophila neurons, follow 9.9-9.11.

2. Trypsinize the cells to release them (see step 4 in section 8 above). To reduce cell aggregation, trypsinize the cells at $60 \%$ or less confluency.

3. Mix $100 \mu \mathrm{L}$ of trypsinized cells with $100 \mu \mathrm{L}$ of trypan blue. Pipette $10 \mu \mathrm{L}$ of the diluted cell mix into a hemocytometer and count the cells.

4. Dilute the cells in media to $2 \times 10^{4}$ cells $/ \mathrm{mL}$.

5. Add $1 \mu \mathrm{L}$ of media to the center of a $30 \mathrm{~mm}$ glass bottom dish to assist in placing the grid and prevent it from drying. Transfer the grid from the PBS on the coverslip to the center of the glass bottom dish. Add $10 \mu \mathrm{L}$ of cell solution to the grid. 
6. Using a brightfield microscope, observe cell adhesion to the grid after $5 \mathrm{~min}$. If a majority of the patterns remain unoccupied, add an additional $10 \mu \mathrm{L}$ drop of the cell solution. Keep the grids and cell solution at $37^{\circ} \mathrm{C}$ during the incubations.

7. Repeat step 9.6 until most patterns are occupied or many occupied patterns begin to have multiple cells. Incubate the grid for $2 \mathrm{~h}$ in the incubator $\left(37^{\circ} \mathrm{C}, 5 \% \mathrm{CO}_{2}\right)$.

8. Flood the dish with $2 \mathrm{~mL}$ of pre-warmed media and incubate overnight $\left(37^{\circ} \mathrm{C}, 5 \% \mathrm{CO}_{2}\right)$.

9. For primary Drosophila neurons, remove the media from the grid-containing dish and plate the cells onto the dish.

10. Wait $30-60 \mathrm{~min}$ for the cells to attach, then add $2 \mathrm{~mL}$ of supplemented Schneider's media.

11. Culture the neurons in a $25{ }^{\circ} \mathrm{C}$ incubator for a minimum of 2-3 days before plunge-freezing.

\section{Imaging and vitrification of patterned grids}

1. Place the glass bottom dish containing the patterned grid and cultured cells on the fluorescence microscope.

2. Acquire images of the grid using brightfield and the appropriate fluorescent channels to detect the pattern and any other labeling in the cells. Ensure the cell density and positioning is suitable for downstream imaging and analysis.

NOTE: Brightfield and fluorescent images were processed in the FIJI software package ${ }^{25}$.

3. Prepare a cryo-plunge freezer; the type of freezing device will depend on availability, cost, and features that are most suitable for the sample.
NOTE: Primary Drosophila neurons were prepared on an automated plunge-freezer, and the BEAS-2B cells were prepared using a semi-automated plunge-freezer.

4. Apply gold fiducials to the samples for proper alignment of the tilt series. Blot samples to remove excess media, then plunge-freeze the samples into a cryogen, such as liquid ethane cooled by liquid nitrogen. For primary Drosophila neurons, blot for $4 \mathrm{~s}$ from the backside. For HeLa and BEAS-2B cells, blot from both sides for 4-6 s. The frozen grids can then be stored in liquid nitrogen until further use.

5. Image vitrified cells in a cryo-electron microscope, operated at $300 \mathrm{kV}$ with a direct electron detector camera. Set up tilt-series collection for each region of interest with software such as SerialEM ${ }^{26}$ for cryo-EM/ cryo-ET data collection.

NOTE: Tilt-series of primary Drosophila neurons were collected on a direct electron detector from $-60^{\circ}$ to $60^{\circ}$ bidirectionally at $2^{\circ}$ increments at $-8 \mu \mathrm{m}$ defocus with a pixel size of $4.628 \AA$ for a total dose of $70-75 \mathrm{e}^{-} / \AA^{2}$. Tilt-series of RSV-infected BEAS-2B were collected on a direct electron detector with an energy filter (20 eV slit) at $-5 \mu \mathrm{m}$ defocus with a pixel size of $4.603 \AA$ and a total dose of $\sim 80 \mathrm{e}^{-} / \AA^{2}$.

6. Process the tilt series to reconstruct tomograms.

NOTE: Tomograms presented here were reconstructed using the IMOD package ${ }^{27}$; lowpass filtering was done using the EMAN2 software package ${ }^{28}$.

\section{Representative Results}

This procedure was used to pattern EM grids for whole cell cryo-ET experiments. The entire workflow presented in this study, including initial cell culture preparations, 
micropatterning (Figure 1), and imaging, encompasses 3-7 days. A two-step procedure was used to generate the antifouling layer by applying PLL to the grid and subsequently linking PEG by addition of the reactive PEG-SVA. The antifouling layer can also be applied in a single step by adding PLL-g-PEG in one incubation. The PLPP gel is a catalyst for the UV micropatterning, which is also available as a less concentrated liquid. The gel allows for patterning at a significantly reduced dose compared to the liquid, which results in much faster patterning. With this system, the actual patterning time of a full TEM grid was $\sim 2$ minutes. The micropatterning workflow alone generally spans 5-6 hours and allows an individual to pattern eight grids for standard cell-culture on TEM grids.

A number of the steps during the micropatterning process require long incubation times (see steps 2.1, 2.3, 6.4). Conveniently, some of these steps, such as PLL passivation (2.1) or PEG-SVA passivation (2.3), may be extended to an overnight incubation. Additionally, grids may be patterned in advance and stored in a solution of the ECM protein or PBS for later use. In our study, these options were valuable in instances where the timing of cell preparation and seeding is critical, such as primary Drosophila neurons and RSVinfection of BEAS-2B cells.

Grids were prepared in a general biosafety-level 2 (BSL-2) lab setting using clean tools, sterile solutions, and included antibiotics/antimycotics in the growth media $6,22,29,30$. For samples particularly sensitive to microbial contamination, the anti-fouling layer and ECM can be applied in a tissue culture hood or other sterile environment. Additionally, the grid could be washed in ethanol between patterning and ECM application. If working with infectious agents, it is important to adapt the procedure to comply with appropriate biosafety protocols.

This workflow and the procedures presented (Figure 1) allowed HeLa cells (Figure 4), RSV-infected BEAS-2B cells (Figure 3, Figure 5), and primary Drosophila larval neurons (Figure 6, Figure 7) to be seeded onto patterned EM grids for optimal cryo-ET data collection.

HeLa cells seeded onto micropatterned TEM grids remain viable as determined by fluorescent staining using a calceinAM and ethidium homodimer-1 based cell viability assay (Figure 4A,B). Using a mixed ECM of collagen and fibrinogen, HeLa cells readily adhere to patterns across the grid (Figure 4A,C). The overall morphology of cells that expand along the pattern is similar to that of cells grown on unpatterned grids (Figure 4C,D). In the case of HeLa cells, the total cell thickness remains $\sim 10 \mu \mathrm{m}$ with significantly thinner areas $\sim 1 \mu \mathrm{m}$ thick near the cell periphery (Figure 4E,F).

For RSV studies, we patterned entire grid squares using a gradient, with a low-dose exposure on the edges and a higher dose pattern towards the center (Figure 3A). Gradient patterns yielded better results when searching for released viruses present near the periphery of cells. With these patterns, cells were found to preferentially adhere to the higher ECM concentration, but are also able to adhere to and grow on the lower ECM concentrations. The relative dose between areas will need to be optimized when using patterns that require multiple doses. If the doses and thus ECM concentrations are too similar or too disparate to one another, the effect of using multiple doses will be lost.

In Figure 3, a TEM grid was patterned and subsequently seeded with RSV infected BEAS-2B cells and used for cryo- 
EM data collection. Figure 4A is a fluorescent image of ECM patterned onto a TEM grid using a gradient pattern. Cell adhesion and growth along the central region of the pattern can be seen in Figure 3B as a brightfield image of the cells 18 hours post-seeding. In Figure 3C, fluorescent signal (red) from replication of RSV-A2mK+ is overlaid with signal from the ECM. The majority of the infected cells are positioned along the higher density central region of the gradient pattern. A low-mag TEM map of the grid post cryo-fixation reveals a number of cells, including RSV-infected cells, positioned on the carbon foil near the center of the grid squares. As previously shown for cells grown on standard TEM grids ${ }^{22}$, tilt-series were located and collected of RSV virions in close proximity to the periphery of infected BEAS-2B cells grown on micropatterned grids (Figure 5A,B). Many of the RSV structural proteins can be identified within the tomograms including nucleocapsid $(\mathrm{N})$ and the viral fusion protein $(\mathrm{F})$ (Figure 5C, blue and red arrows respectively).

For primary Drosophila neuron studies, it was found that the narrow pattern, near the resolution limit offered by the software (where the thickness of the pattern was $2 \mu \mathrm{m}$ ), allowed from one to a few cells to be isolated within a grid square (Figure 6). The neuronal soma was able to extend its neurites over a period of several days within the pattern. This allowed easy identification and tilt series acquisition of the neurites compared to neurons cultured on unpatterned grids (Figure 7). It was also found that fluorescently-labeled concanavalin $A$, a lectin that has been used as an ECM for in vitro Drosophila neuronal cultures ${ }^{20,21}$, is amenable for patterning.

Drosophila neurons from third instar larvae were isolated according to previously published protocols ${ }^{20,21,31}$. The neuronal preparations were applied to micropatterned cryo-
EM grids where concanavalin A was deposited on the pattern to regulate cell placement, spreading, and organization. The neurons on patterned or unpatterned grids were allowed to incubate for a minimum of $48-72$ hours, and the grids were then plunge frozen. A representative image of a micropatterned EM grid with several Drosophila neurons distributed across the patterned regions is shown in Figure 6A. These neurons, derived from a transgenic fly strain that has pan-neuronal GFP expression in the membrane, can be easily tracked by light microscopy not only due to its fluorescent labeling, but also because of its location within the micropatterns. While neurons cultured on unpatterned grids can also be tracked through its GFP signaling by light microscopy (Figure 7A, yellow circle), locating them in cryo-EM became substantially more difficult due to the presence of cellular debris and contamination from the media (Figure 7B, yellow circle). Such presence was lessened for neurons on patterned grids, likely due to the PEG in the anti-fouling layer of the non-patterned regions repelling the cell debris from adhering. Due to the dimensions of the neuron cell body and the extended neurites (Figure 6A,B, yellow circle), cryo-ET tilt series were collected along thinner regions of the cells (Figure 6C,D, red circle). The neuronal cell membrane, a mitochondrion (cyan), microtubules (purple), actin filaments (blue), vesicular structures (orange and green), and macromolecules such as ribosomes (red) were well resolved in higher-magnification image montages and slices through the 3D tomogram (Figure 6E). While similar sub-cellular features can be seen from 3D tomograms of unpatterned neurons (Figure 7E), the difficulty in locating viable cellular targets for data collection decreased throughput substantially.

In Figure 8, representative images from grids with some of these issues have been assembled to assist in their 


\section{Prepare grids}

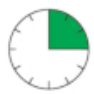

Approx. 3 hours

\begin{tabular}{c|l} 
Load grid onto microscope \\
$\begin{array}{l}\text { Approx. } \\
20 \text { min/grid }\end{array}$ & $\begin{array}{l}\text { Moad/design pattern template } \\
\text { Position pattern on grid } \\
\text { Pattern grid } \\
\text { Wash grid in PBS }\end{array}$ \\
\hline
\end{tabular}

\section{ECM and cell seeding}

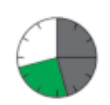

2-3 hours

iime varies significantly based on workflow Incubate grid in PLL and wash Add PLPP gel and dry

Incubate grid in ECM and wash

Prepare cells

Add cells to grid

Add media and grow in incubator

Screen grids by light microscopy

Plunge-freeze grids

Cryo-CLEM or FIB-SEM (optional)
Carbon coat and glow discharge grids Incubate grid in PEG-SVA and wash Add PDMS stencil over grid on coverslip
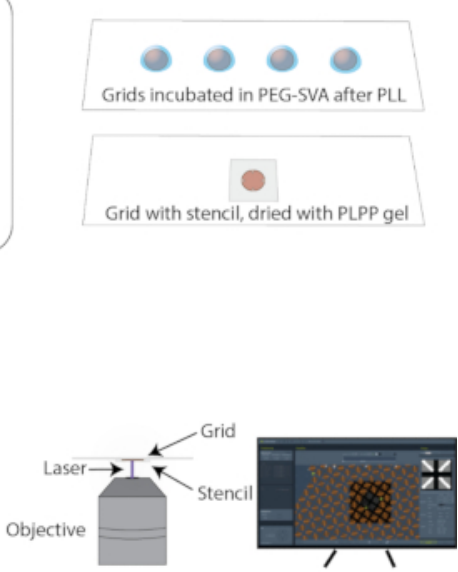

Cryo-preparation and data-collection

Cryo-electron tomography

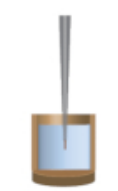

Plunge freeze
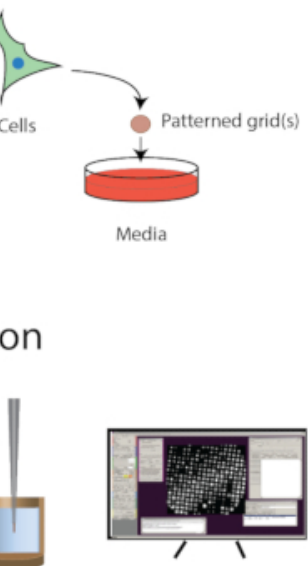

Media

Figure 1: General workflow of micropatterning for cryo-EM. The workflow can be roughly divided four parts: Grid preparation, micropatterning, ECM and cell seeding, and cryo-preparation and data collection. Major steps of each section are listed below the headings and the approximate time to complete each section is shown to the left. Please click here to view a larger version of this figure. 

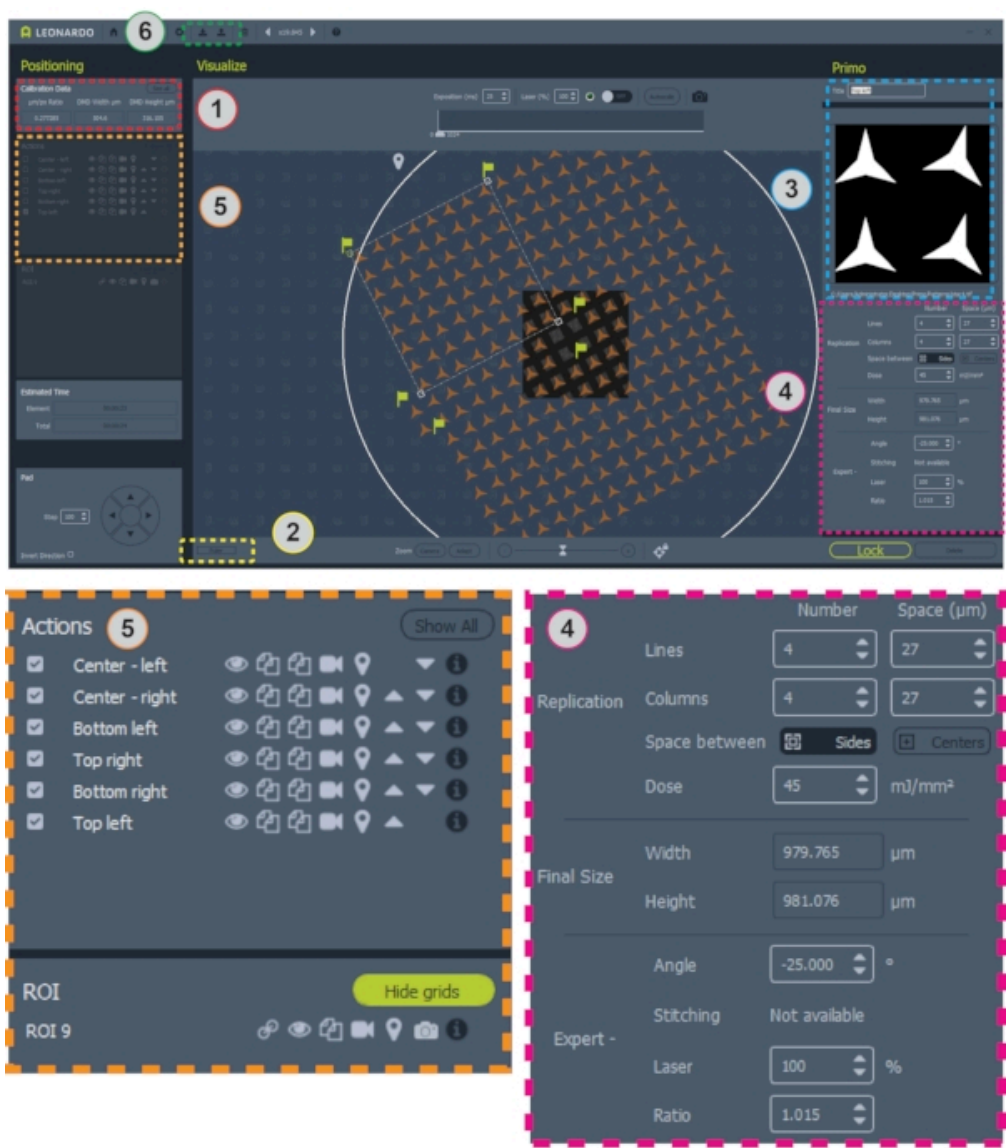

Figure 2: Screen shot of the software with pattern positioned on grid. Area 1 contains the $\mu \mathrm{m} /$ pix ratio for pattern design. Area 2 is the ruler for measuring a grid. Area 3 is where to add or change patterns and ROls. Area 4 contains all of the information for pattern positioning and dose. Area 5 contains options for patterns, including toggling overlays, copying or deleting patterns, and selecting patterns for micropatterning. Area 6 is where templates can be saved and loaded. Larger views of areas 4 and 5 are shown below for clarity. Please click here to view a larger version of this figure. 

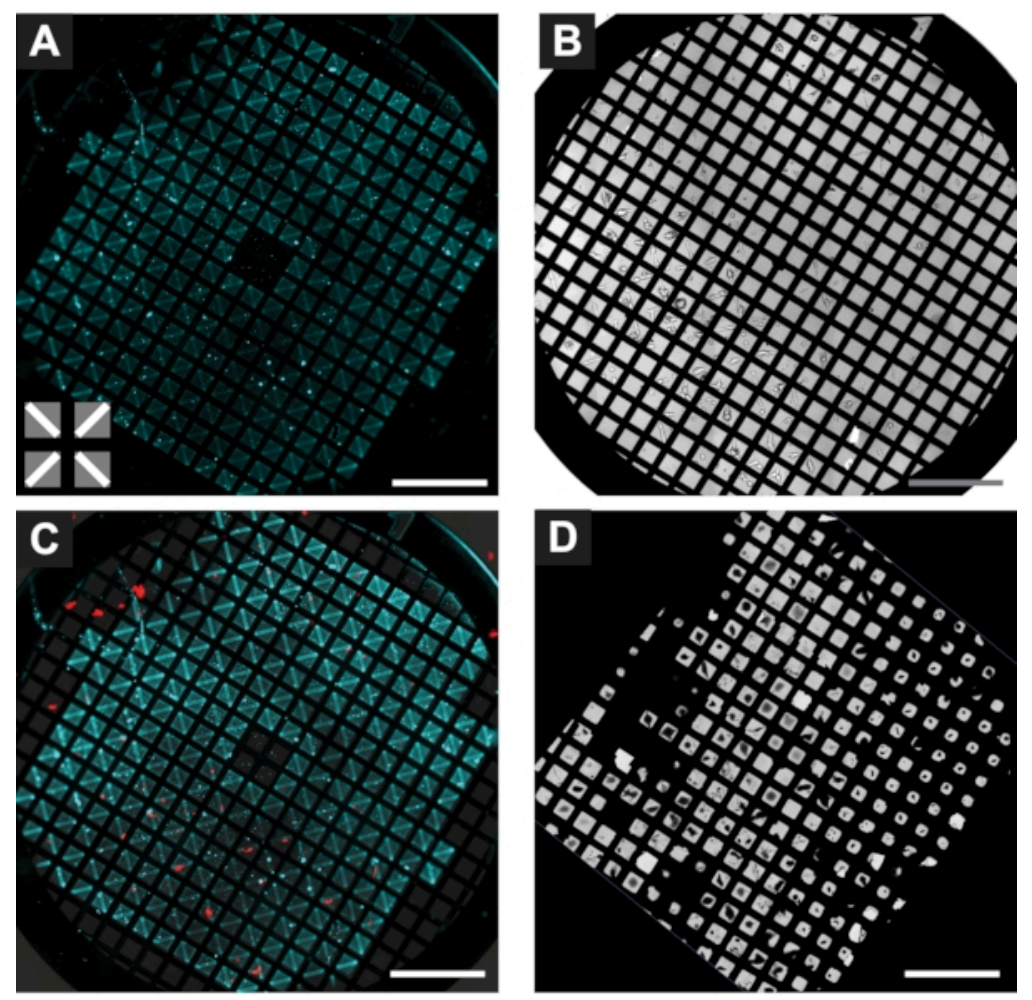

Figure 3: RSV-infected BEAS-2B cells on the patterned cryo-TEM grid. (A) Fluorescent image of the patterned grid after addition of fluorescently labeled ECM. The input pattern is shown in the lower left corner. (B) Brightfield image of BEAS-2B cells grown on the grid in A. (C) Merge of the image in A (cyan) and B (grey) with fluorescent image of RSV-infected cells (red) immediately prior to plunge-freezing; infected cells express mKate-2. Scale bars are $500 \mu m$. (D) Low-magnification cryo-TEM map of the grid in B after plunge-freezing. Fluorescent images are pseudocolored. Scale bars are $500 \mu \mathrm{m}$. Please click here to view a larger version of this figure. 

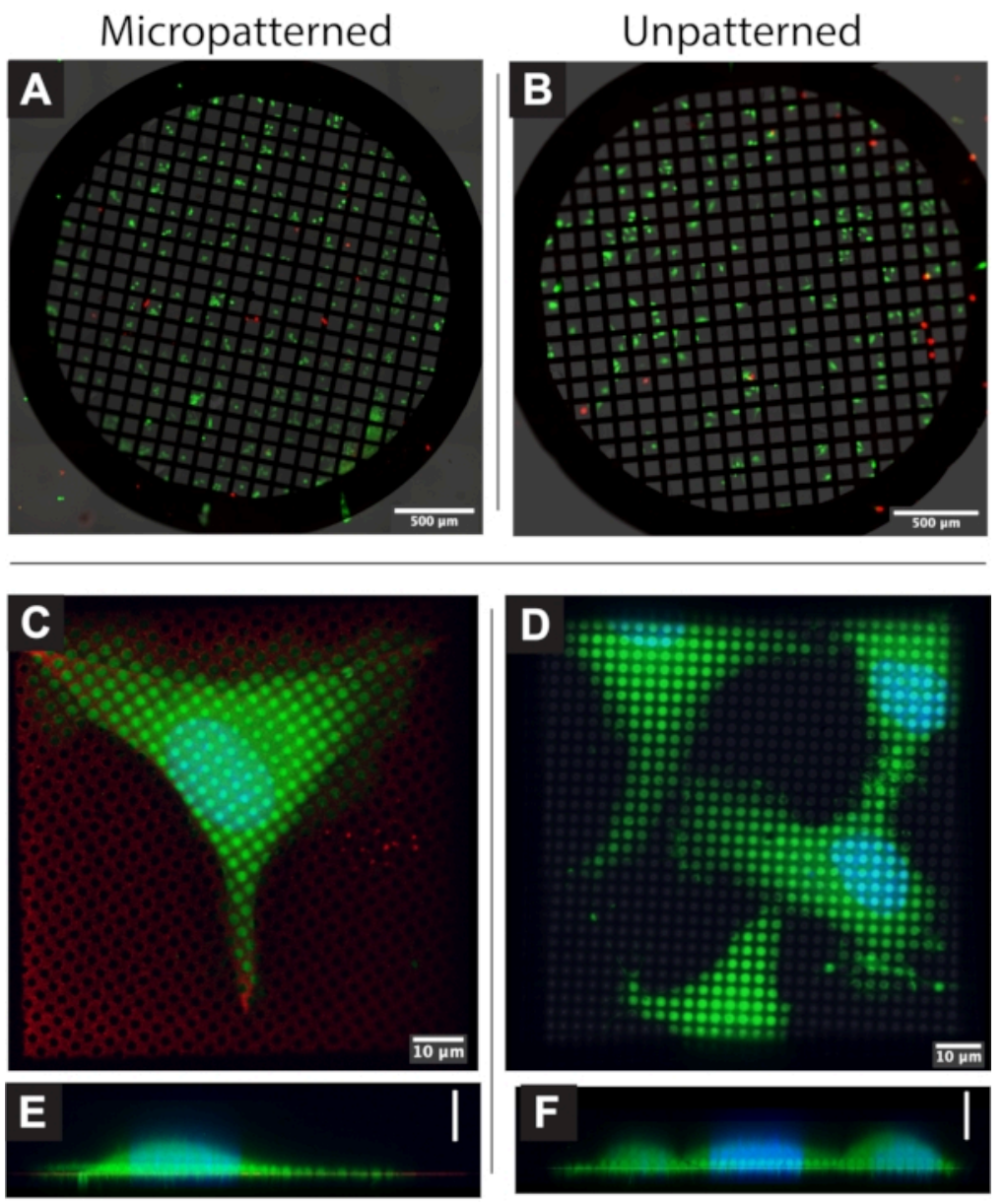

Figure 4: Live/Dead staining of patterned and unpatterned cells. (A) Fluorescent image of HeLa cells grown on a patterned grid and stained with calcein-AM (live cell stain, green) and ethidium homodimer-1 (dead cell stain, red). (B) HeLa cells grown on an unpatterned grid and stained as in A. (C) Projection of confocal z-stacks of a HeLa cell on a patterned Quantifoil R2/2 grid with $0.01 \mathrm{mg} / \mathrm{mL}$ collagen and fibrinogen 647 ECM (red). Cell was stained with calcein-AM (green) and Hoechst-33342 (blue). (D) HeLa cells on unpatterned grid incubated with $0.01 \mathrm{mg} / \mathrm{mL}$ collagen and fibrinogen 647 ECM, incubated and stained with calcein-AM and Hoecsht-33342. The fluorescent images were merged with transmitted light (grayscale). (E) X,Z projection of C. (F) X,Z projection of D. Images are pseudocolored. Scale bars in (A) and (B) are $500 \mu \mathrm{m}$; scale bars in $(C)-(F)$ are $10 \mu \mathrm{m}$. Please click here to view a larger version of this figure. 

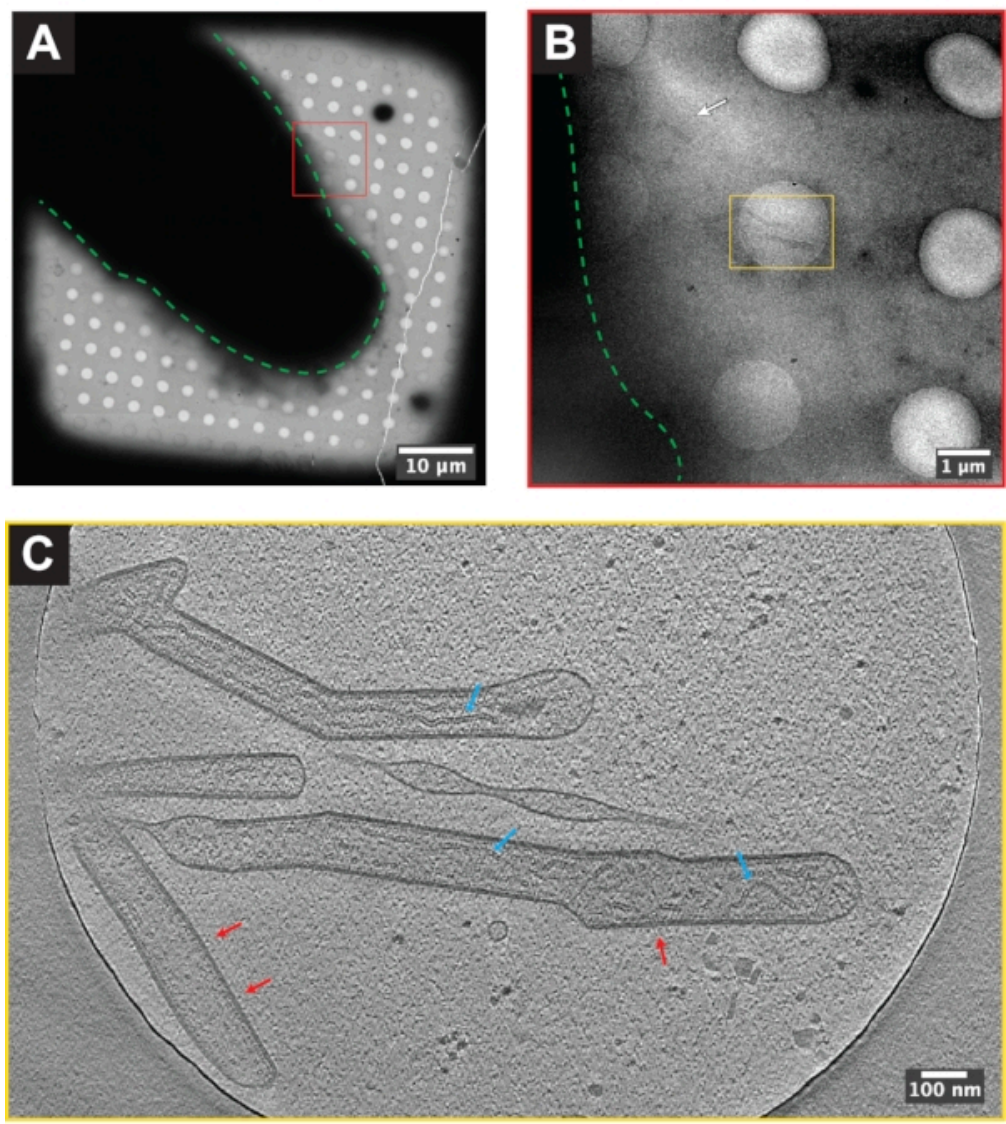

Figure 5: Cryo-ET of RSV-infected BEAS-2B cell on the patterned cryo-TEM grid. (A) Cryo-EM grid square map of RSV infected BEAS-2B cell. Approximate cell boundary is indicated by the dashed green line. (B) Higher resolution image of area boxed in red in (A). Approximate cell boundary is indicated by dashed green line. RSV virions can be seen near the cell periphery (white arrow and yellow box). (C) Single z-slice from tomogram collected in the area of the yellow box in (B). Red arrows point to RSV F fusion protein, blue arrows point to the ribonucleoprotein (RNP) complex. The scale bars in (A)-(C) are embedded in the image. Please click here to view a larger version of this figure. 

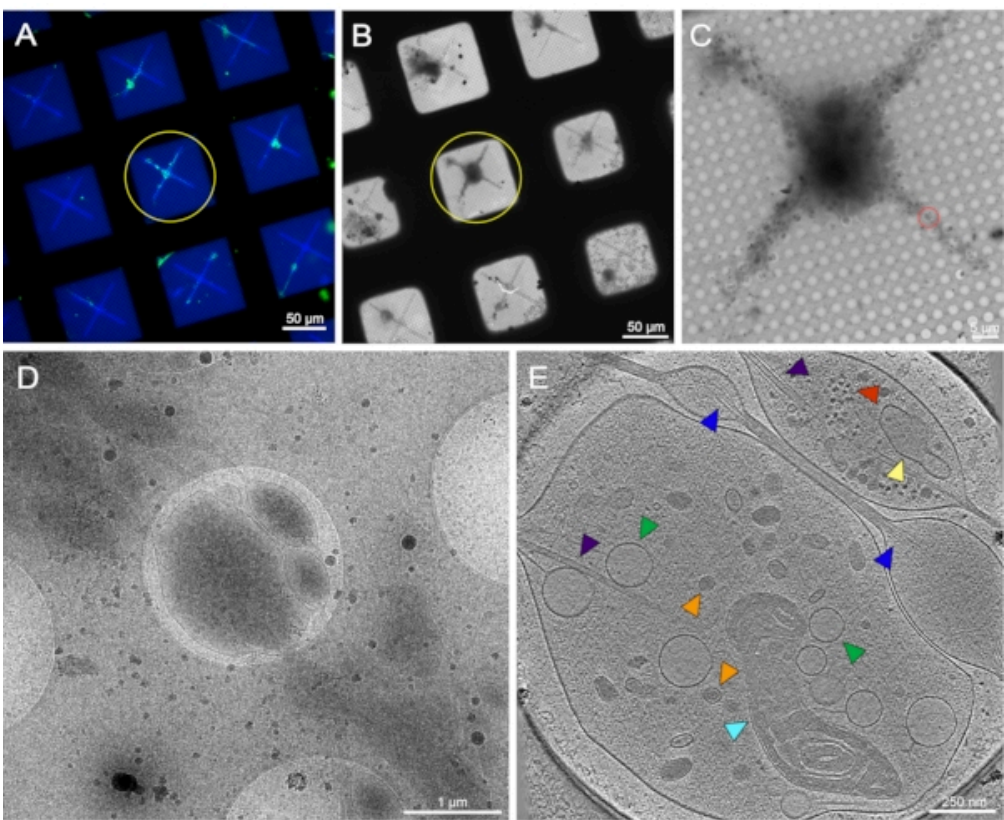

Figure 6: Primary neurons derived from the brains of $3^{\text {rd }}$ instar Drosophila melanogaster larvae on the patterned cryo-TEM grid. (A) Overlaid live-cell fluorescence microscopy grid montage of Drosophila neurons expressing membranetargeted GFP on patterned grid squares with $0.5 \mathrm{mg} / \mathrm{mL}$ fluorescent concanavalin A. Green: Drosophila neurons. Blue: Photopattern. (B) Cryo-EM image montage of the grid in (A) after cryo-preservation. Yellow circle notes the same grid square as in (A). (C) Cryo-EM image montage of the square highlighted by the yellow circle in (A) and (B). (D) Higher magnification image of the area bounded by the red circle in (C), where a tilt series was collected on the cell's neurites. E. $25 \mathrm{~nm}$ thick slice of a tomogram reconstructed from the tilt series that was acquired from the red circle in (C). Various organelles can be seen in this tomogram, such as the mitochondria (cyan), microtubules (purple), dense core vesicles (orange), light vesicles (green), the endoplasmic reticulum (yellow), and actin (blue). Macromolecules, such as ribosomes (red), can also be seen in the upper right corner. Fluorescent images are pseudocolored. The scale bars in (A)-(E) are embedded in the image. Please click here to view a larger version of this figure. 

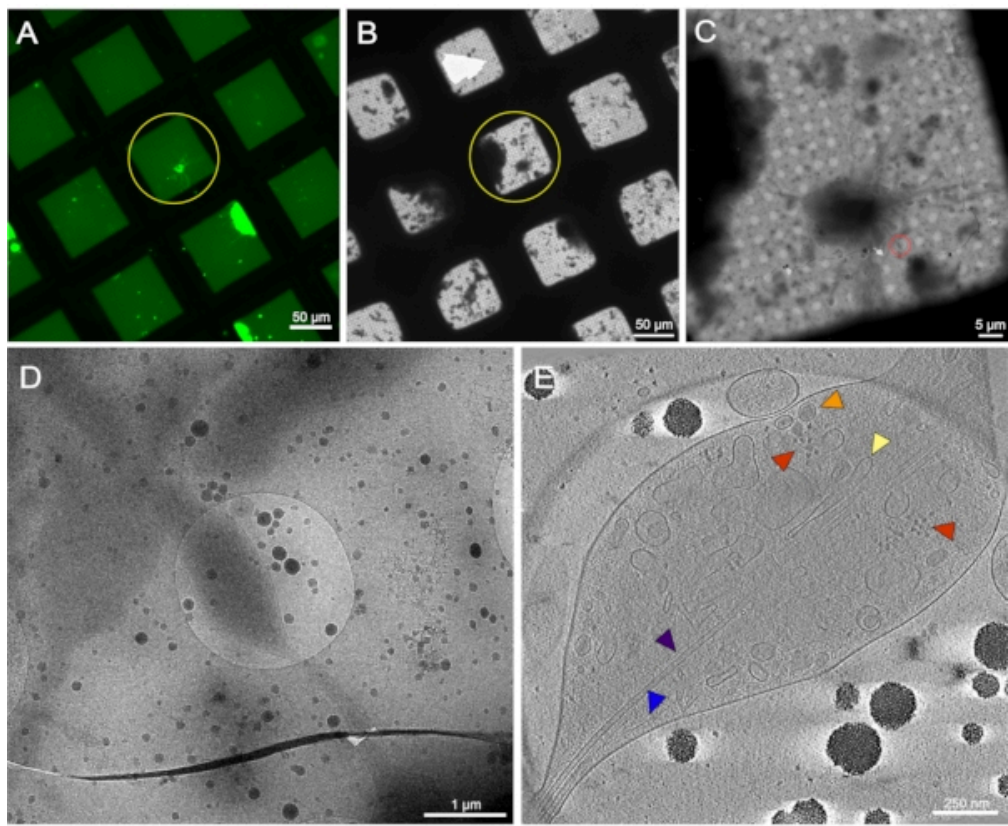

Figure 7: Primary neurons derived from the brains of $3^{\text {rd }}$ instar Drosophila melanogaster larvae on unpatterned grids. (A) Live-cell fluorescence microscopy grid montage of Drosophila neurons expressing membrane-targeted GFP on grid squares with $0.5 \mathrm{mg} / \mathrm{mL}$ concanavalin A. Green: Drosophila neurons. (B) Cryo-EM grid montage of the same grid in (A) after plunge-freezing. Yellow circle shows the same grid square as in (A). Note the presence of cellular debris and media contamination, which made target identification difficult compared to patterned grids. (C) Cryo-EM image montage of the square highlighted by the yellow circles in the (A) and (B) maps. (D) Higher magnification image of the area bounded by the red circle in (C), where a tilt series was collected on the cell's neurites. (E) $25 \mathrm{~nm}$ thick slice of the reconstructed tomogram from the tilt series from (C) and (D). A number of organelles are visible in this tomogram, such as microtubules (purple), actin (blue), the endoplasmic reticulum (yellow), and dense core vesicles (orange). Macromolecules, such as ribosomes (red), can also be seen. Fluorescent images are pseudocolored. The scale bars in (A)-(E) are embedded in the image. Please click here to view a larger version of this figure. 

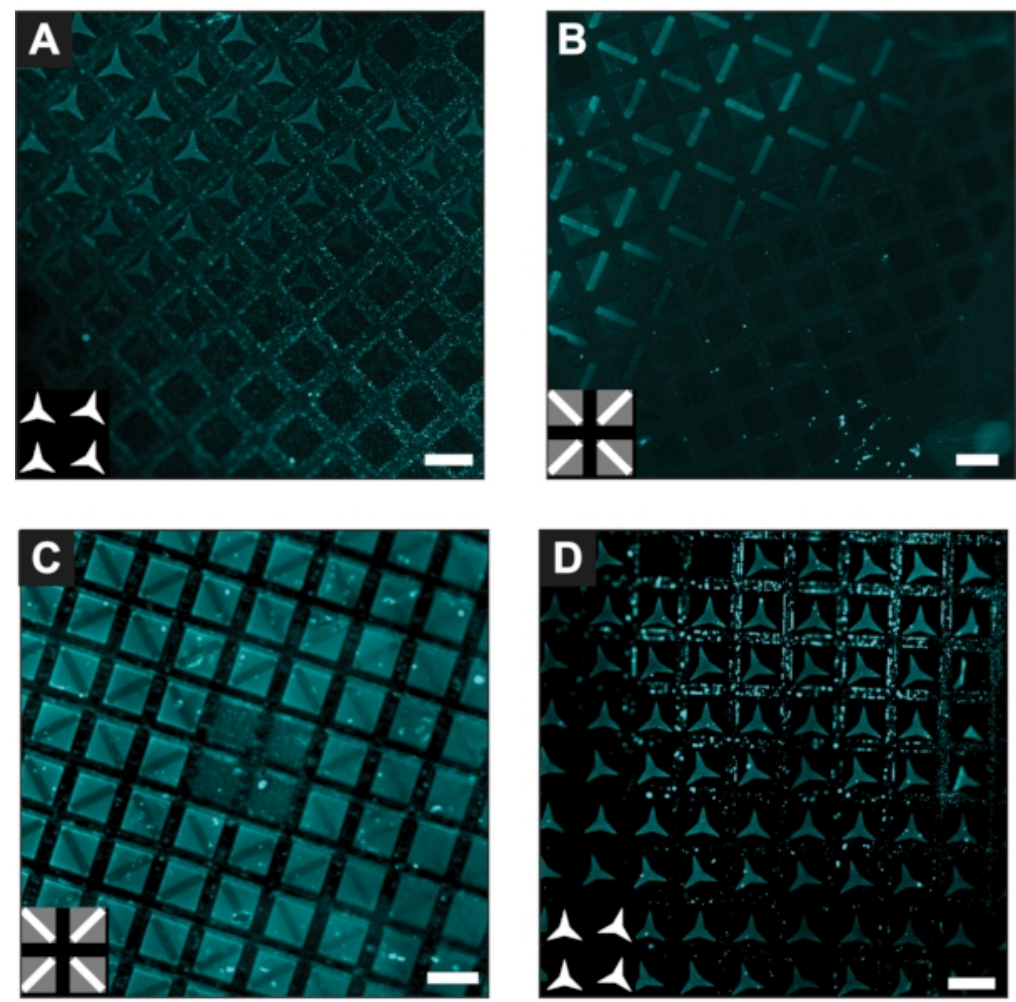

Figure 8: Examples of possible problems with patterning. Fluorescent images of labeled ECM deposited on micropatterned grids. (A) Uneven patterning across the grid due to uneven distribution of PLPP gel. (B) ECM cannot adhere to areas covered by the PDMS stencil during patterning. (C) Saturated gradient pattern (right side) or inverted pattern (left) on a grid patterned with too high total dose. (D) ECM is adhering to areas on the grid bars as well as patterned area due to reflections of the UV laser during patterning. Images are pseudocolored; input pattern is shown in the lower left; scale bars are $100 \mu \mathrm{m}$. Please click here to view a larger version of this figure. 


\begin{tabular}{|c|c|c|}
\hline Issue & Potential cause(s) & Troubleshooting \\
\hline \multicolumn{3}{|l|}{ Micropatterning } \\
\hline \multirow{2}{*}{$\begin{array}{l}\text { Cannot see illumination } \\
\text { from PRIMO laser }\end{array}$} & - Light path is not set up correctly & \multirow{2}{*}{$\begin{array}{l}\text { - Check that the microscope } \\
\text { light path is set up properly }\end{array}$} \\
\hline & $\begin{array}{l}\text { - PRIMO laser is not on } \\
\text { or laser is interlocked }\end{array}$ & \\
\hline \multirow[t]{2}{*}{ Many broken grid squares } & $\begin{array}{l}\text { • Touching grid foil with } \\
\text { tweezers or pipet while handling }\end{array}$ & - Handle grids with care \\
\hline & $\begin{array}{l}\text { - Grid dried out during } \\
\text { incubations or washing }\end{array}$ & $\begin{array}{c}\text { - Do not allow grid to dry } \\
\text { during washes and incubations }\end{array}$ \\
\hline \multirow[t]{4}{*}{ Large unpatterned areas } & - Insufficient gel coverage & $\begin{array}{c}\text { - Ensure gel spreads evenly } \\
\text { over grid while adding }\end{array}$ \\
\hline & - Grid foil out of focus during patterning & - Add an additional microliter of gel \\
\hline & -Area covered by stencil & $\begin{array}{l}\text { - Check focus before } \\
\text { patterning each region }\end{array}$ \\
\hline & & - Carefully center grid in stencil \\
\hline \multirow[t]{3}{*}{ Saturated or inverted pattern } & - Incorrect dose & - Try a range of total doses for pattern \\
\hline & - Insufficient gel coverage & - Ensure grid is evenly covered with gel \\
\hline & & $\begin{array}{l}\text { - Try different values } \\
\text { for grayscale patterns }\end{array}$ \\
\hline \multirow[t]{3}{*}{ Blurry pattern } & - Poor focus during patterning & $\begin{array}{l}\text { - Repeat PRIMO calibration } \\
\text { at same height as sample }\end{array}$ \\
\hline & - Incorrect calibration & - Focus on grid foil before patterning \\
\hline & & $\begin{array}{l}\text { - Divide pattern into additional } \\
\text { regions for patterning }\end{array}$ \\
\hline \multirow[t]{2}{*}{ ECM adhereing outside of pattern } & \multirow[t]{2}{*}{ - Reflections from gel or dust } & - Ensure gel is dry before patterning \\
\hline & & $\begin{array}{l}\text { - Make sure coverslip and } \\
\text { objective lens are clean }\end{array}$ \\
\hline ECM not visible after patterning & - Photo bleaching & $\begin{array}{l}\text { - Minimize light exposure } \\
\text { to ECM prior to imaging }\end{array}$ \\
\hline
\end{tabular}




\begin{tabular}{|c|c|c|}
\hline & \multirow[b]{2}{*}{ - Incorrect dose during patterning } & \multirow[b]{2}{*}{$\begin{array}{c}\cdot \text { Try a range of total } \\
\text { dose values for pattern }\end{array}$} \\
\hline & & \\
\hline & - Insufficient ECM incubation time & - Increase incubation time for ECM \\
\hline \multicolumn{3}{|l|}{ Cell seeding } \\
\hline \multirow[t]{4}{*}{ Cells clumping } & - Over digestion & $\begin{array}{l}\text { - Use lower percentage of trypsin } \\
\text { or time for release of adherent cells }\end{array}$ \\
\hline & - High cell density & $\begin{array}{l}\text { - Passage and/or digest } \\
\text { cells at lower confluency }\end{array}$ \\
\hline & & - Do not agitate cells during release \\
\hline & & $\begin{array}{l}\text { - Gently pipet cell solution } \\
\text { or use cell strainers }\end{array}$ \\
\hline \multirow[t]{2}{*}{ Cells not adhering to patterned areas } & - ECM is not suitable for cell type & $\begin{array}{l}\text { • Try different ECM } \\
\text { concentrations and composition }\end{array}$ \\
\hline & $\begin{array}{c}\cdot \text { Cells viability is } \\
\text { decreased prior to seeding }\end{array}$ & $\begin{array}{l}\text { - Ensure cell culture and cell release } \\
\text { conditions are not damaging cells }\end{array}$ \\
\hline \multirow[t]{2}{*}{ Cells not expanding after adhesion } & \multirow{2}{*}{$\begin{array}{l}\text { - ECM or pattern not } \\
\text { suitable for cell type }\end{array}$} & - Try different patterns and ECM \\
\hline & & $\begin{array}{l}\text { • In some cases a more } \\
\text { continuous foil (R1.2/20 vs R2/1) } \\
\text { may promote cell expansion }\end{array}$ \\
\hline
\end{tabular}

Table 1: Potential issues during micropatterning. This table describes some issues a user may experience during micropatterning or cell-seeding. Potential causes and troubleshooting are provided for each issue. Representative images of some problems can be seen in Figure 8.

\section{Discussion}

Modern, advanced electron microscopes and software packages now support streamlined automated cryo-EM and cryo-ET data collection where hundreds to thousands of positions can be targeted and imaged within a few days $^{32,33,34,35}$. One significant limiting factor for whole-cell cryo-ET workflows has been obtaining sufficient numbers of collectable targets per grid. Recently, a number of groups have developed protocols for micropatterning grids for cryo-EM, with one advantage being improved data collection efficiency ${ }^{16,17,18}$. Here a protocol is presented for using a commercially available micropatterning system to micropattern TEM grids for cryo-ET studies of primary Drosophila neurons and cultured human cell lines (uninfected or RSV-infected). This micropatterning system is versatile and many steps can be optimized and tailored to fit specific 
experimental goals. A user with TEM and fluorescence microscopy experience can quickly become skilled in grid preparation and micropatterning. With careful practice, good results should be achievable after a few iterations. Below, some of the options available, user considerations, potential benefits, and future applications of micropatterning for cryoEM are discussed.

One of the important considerations for whole cell cryo-ET is EM grid selection. EM grids are composed of two parts: a mesh frame (or structural support) and the foil (or film), which is the continuous or holey film surface on which cells will grow. Copper mesh grids are commonly used for cryoEM of proteins and isolated complexes. However, they are unsuitable for whole-cell cryo-ET due to the cytotoxicity of copper. Instead, a gold mesh is commonly used for cellular tomography. Other options include nickel or titanium, which may provide benefits over gold such as increased rigidity ${ }^{16}$. EM grids are available with different mesh dimensions to support a range of applications. Larger mesh sizes provide more room for cells to grow between grid bars and more areas that are amenable for tilt series collection, though at the cost of increased overall specimen fragility. The most commonly used foil is perforated or holey amorphous carbon, such as Quantifoils or C-flat grids. Biological targets can be imaged either through the holes in the carbon or through the electrontranslucent carbon. Grids such as $\mathrm{R} 2 / 1$ or $\mathrm{R} 2 / 2$, where the holes are $2 \mu \mathrm{m}$ wide that are spaced 1 and $2 \mu \mathrm{m}$ apart respectively, provide a large number of holes and thus a large number of potential areas for data collection. However, some cells may grow and expand better on more uniform surfaces such as R 1.2/20 grids or continuous carbon. For downstream sample processing by focused-ion beam milling (cryo-FIB), the foil is removed through milling, reducing concerns over the continued presence of the underlying film. As with the mesh, foils from other materials are also available, with the patterning protocol presented here being equally suitable for $\mathrm{SiO}_{2}$ grids. Commonly used grids include gold Quantifoil, continuous carbon, or $\mathrm{SiO}_{2}$ film 200-mesh grids $(\sim 90 \mu \mathrm{m}$ spacing between grids bars) for whole-cell cryo-ET.

There are a number of considerations when designing a pattern. A majority of these decisions are guided by the cell type and purpose of the experiment. A good starting point is to choose a pattern that approximates the shape and dimensions of the cells in culture. Many studies have demonstrated significant effects of pattern shape on cell growth and cytoskeletal arrangement ${ }^{13,36,37}$. Special care should be taken during pattern design if this could alter the target of interest. Several patterns for each cell type were tested to determine which patterns promoted cellular adhesion and growth. The flexibility of the micropatterning system permits the testing of multiple patterns on a single grid and changing patterns for different grids within a single experiment. Larger patterns $(\sim 50-90 \mu \mathrm{m})$, such as those used here, increase the likelihood that multiple cells adhere to a single region of the pattern and allow cells to expand and extend after adhesion. More constrained patterns (20-30 $\mu \mathrm{m})$ may be appropriate in experiments where cell isolation is more critical than cell expansion, such as for focusedion beam milling (cryo-FIB) experiments. For tomography applications, one may need to consider the impact of the tiltaxis. If a pattern is positioned such that all cells grow parallel to one another in a single direction, it is possible that all of the cells will be perpendicular to the tilt-axis when loaded onto the microscope stage, resulting in a lower quality of data.

On unpatterned grids, cells often preferentially adhere to the grid bars, where they cannot be imaged by TEM. Even on patterned grids, cells are often observed to be positioned in 
the corners of grid squares partially on both the patterned carbon foil and grid bar. Recently, micropatterning was used to intentionally position part of the cell over the grid bar $^{18}$. This could be considered for experiments where it is not critical to have the entire cell periphery on the foil. This can be especially important for cells that can grow larger than a single grid square, such as primary neurons growing over multiple days.

There are many tools that can be used to design a pattern. Here, the pattern was limited to less than 800 pixels in any dimension such that the pattern can be rotated to any angle and still fit within the maximum area that can patterned in a single projection by this micropatterning system. This allows the user to rotate the pattern to be properly oriented with the grid regardless of the orientation of the grid on the microscope. Here, the grid was divided into six patterning areas. Primarily, this allows focus adjustment between different regions of the grid. Gold grids, in particular, are very malleable and may not lay down completely flat on the glass. Proper focus is essential for clean, refined patterning results. By using segmented patterns, only minor adjustments to the pattern position need to be made if the grid shifts slightly during patterning process, though this is usually not an issue when using the PLPP gel with the PDMS stencils. Finally, the central four grid squares of the grid remained unpatterned. This supports a user being able to clearly identify the center of the grid, which is very useful for correlativeimaging experiments.

The patterning software for this micropatterning system, Leonardo, also has more advanced features such as stitching and the ability to import patterns as PDFs, which are beyond the scope of this protocol. This software also includes microstructure detection and automated pattern positioning that can be used on TEM grids. This feature is most useful when the grid is very flat and can be patterned without the need to adjust focus between different areas.

Selection of an ECM protein can have a significant impact on cell adhesion and expansion. Some cells are known to undergo physiological changes when grown on specific substrates $^{38}$. Multiple ECM proteins and concentrations were tested for any new cell type based on prior work reported in the literature. Laminin, fibrinogen, fibronectin, and collagen are widely used for cultured cells and can be used as a starting point if other data is not available. However, other ECM proteins must also be considered if the commonly used ECM proteins fail to confer proper adherence properties for the cells. This was particularly true for primary Drosophila neurons, as a high-concentration of the plant lectin concanavalin A was necessary for proper cellular adherence. The compatibility of cellular adhesion and growth with the ECM can be tested by patterning on glass dishes or slides prior to transitioning to TEM grids. This pre-screening approach is time and cost-effective if a large number of combinations need to be examined. The inclusion of a fluorescently conjugated ECM protein is valuable for assessing the success and quality of patterning.

Cell seeding is one of the most important steps for whole cell cryo-ET, either with or without micropatterning 6,16,39. For primary Drosophila or other neurons, which are fragile, unstable in suspension, and may be limited in quantity, single seeding approaches are preferred over monitored, sequential cell seeding. A single seeding step at an optimized cell density, as described in the protocol for Drosophila neurons, is a viable option for most cell types. However, it is also possible to seed cells onto the substrate at a lower initial concentration and add more cells in a monitored fashion 
as described here and in other literature ${ }^{18}$. This sequential seeding can provide more consistent results in some cases. Similar to standard cell culture, care should always be taken to maintain cell viability and minimize cell clumping during isolation.

When first starting with micropatterning, there are a few potential pitfalls that are detrimental to the final result. Careful grid handling and sterile technique, a uniform distribution of the PLPP gel, proper dose and focus during patterning, and maintenance of cell viability prior to seeding are among the most important considerations for success. A list of some of the potential issues as well as solutions were assembled in

\section{Table 1.}

Micropatterned grids can be used to help position cells to establish a consistent cell density across the grid and to position regions of interest in areas suitable for tilt-series collection $^{16,18}$. The placement and positioning of cells can be used as fiducial markers for correlation in cryo-CLEM experiments, reducing the need for fragile finder-grids and fluorescent fiducial markers. However, it should be noted that such fiducial markers may still be useful for sub-micrometer accuracy correlation ${ }^{29,40}$. Furthermore, an even distribution of isolated cells is also highly beneficial for focused-ion beam milling (cryo-FIB) experiments to maximize the number of cells from which lamella can be cut ${ }^{16}$.

The addition of micropatterning to cryo-EM workflows will result in measurable improvements in data throughput and potentially enable new experiments. As the technique is further adopted and developed, more advanced applications of micropatterning including ECM gradients, multiple ECM depositions, and microstructure assembly will further expand the capabilities of cryo-ET to study biological targets and processes in full cellular context.

\section{Disclosures}

The authors have nothing to disclose.

\section{Acknowledgments}

We thank Dr. Jill Wildonger, Dr. Sihui Z. Yang, and Mrs. Josephine W. Mitchell in the Department of Biochemistry, University of Wisconsin, Madison for generously sharing the elav-Gal4, UAS-CD8::GFP fly strain (Bloomington stock center, \#5146). We would also like to thank Dr. Aurélien Duboin, Mr. Laurent Siquier, and Ms. Marie-Charlotte Manus from Alvéole and Mr. Serge Kaddoura from Nanoscale Labs for their generous support during this project. This work was supported in part by the University of Wisconsin, Madison, the Department of Biochemistry at the University of Wisconsin, Madison, and public health service grants R01 GM114561, R01 GM104540, R01 GM104540-03W1, and U24 GM139168 to E.R.W. and R01 Al150475 to P.W.S. from the NIH. A portion of this research was supported by NIH grant U24 GM129547 and performed at the PNCC at OHSU and accessed through EMSL (grid.436923.9), a DOE Office of Science User Facility sponsored by the Office of Biological and Environmental Research. We are also grateful for the use of facilities and instrumentation at the Cryo-EM Research Center in the Department of Biochemistry at the University of Wisconsin, Madison.

\section{References}

1. Nogales, E., Scheres, S. H. Cryo-EM: A unique tool for the visualization of macromolecular complexity. Molecular Cell. 58 (4), 677-689 (2015). 
2. Martynowycz, M. W., Gonen, T. From electron crystallography of 2D crystals to MicroED of 3D crystals. Current Opinion in Colloid and Interface Science. 34, 9-16 (2018).

3. Wagner, J., Schaffer, M., Fernandez-Busnadiego, R. Cryo-electron tomography-the cell biology that came in from the cold. FEBS Letters. 591 (17), 2520-2533 (2017).

4. Wan, W., Briggs, J. A. Cryo-electron tomography and subtomogram averaging. Methods in Enzymology. 579, 329-367 (2016).

5. Bäuerlein, F. J., Pastor-Pareja, J. C., FernándezBusnadiego, R. Cryo-electron tomography of native Drosophila tissues vitrified by plunge freezing. bioRxiv. e437159, (2021).

6. Hampton, C. M. et al. Correlated fluorescence microscopy and cryo-electron tomography of virusinfected or transfected mammalian cells. Nature Protocols. 12 (1), 150-167 (2017).

7. Hsieh, C. E., Leith, A., Mannella, C. A., Frank, J., Marko, M. Towards high-resolution three-dimensional imaging of native mammalian tissue: Electron tomography of frozenhydrated rat liver sections. Journal of Structural Biology. 153 (1), 1-13 (2006).

8. Al-Amoudi, A., Norlen, L. P., Dubochet, J. Cryo-electron microscopy of vitreous sections of native biological cells and tissues. Journal of Structural Biolology. 148 (1), 131-135 (2004).

9. Rigort, A. et al. Focused ion beam micromachining of eukaryotic cells for cryoelectron tomography. Proceedings of the National Academy of Sciences. 109 (12), 4449-4454 (2012).
10. Gorelick, S. et al. PIE-scope, integrated cryo-correlative light and FIB/SEM microscopy. Elife. 8, e45919 (2019).

11. Wu, G. H. et al. Multi-scale 3D cryo-correlative microscopy for vitrified cells. Structure. 28 (11), 1231-1237 e1233, (2020).

12. Turk, M., Baumeister, W. The promise and the challenges of cryo-electron tomography. FEBS Letters. 594 (20), 3243-3261 (2020).

13. Théry, M. Micropatterning as a tool to decipher cell morphogenesis and functions. Journal of Cell Science. 123 (24), 4201-4213 (2010).

14. Tseng, Q. et al. Spatial organization of the extracellular matrix regulates cell-cell junction positioning. Proceedings of the National Academy of Sciences. 109 (5), 1506-1511 (2012).

15. Hardelauf, $\mathrm{H}$. et al. Micropatterning neuronal networks. Analyst. 139 (13), 3256-3264 (2014).

16. Toro-Nahuelpan, M. et al. Tailoring cryo-electron microscopy grids by photo-micropatterning for in-cell structural studies. Nature Methods. 17 (1), 50-54 (2020).

17. Engel, L. et al. Extracellular matrix micropatterning technology for whole cell cryogenic electron microscopy studies. Journal of Micromechanics and Microengineering. 29 (11), (2019).

18. Engel, L. et al. Lattice micropatterning for cryo-electron tomography studies of cell-cell contacts. bioRxiv. e272237, (2021).

19. Sibert, B. S., Kim, J. Y., Yang, J. E., Wright, E. R. Wholecell cryo-electron tomography of cultured and primary eukaryotic cells on micropatterned TEM grids. bioRxiv. e447251 (2021). 
20. Egger, B., van Giesen, L., Moraru, M., Sprecher, S. G. In vitro imaging of primary neural cell culture from Drosophila. Nature Protocols. 8 (5), 958-965 (2013).

21. Lu, W., Lakonishok, M., Gelfand, V. I. Kinesin-1powered microtubule sliding initiates axonal regeneration in Drosophila cultured neurons. Molecular Biology of the Cell. 26 (7), 1296-1307 (2015).

22. Ke, Z. et al. The morphology and assembly of respiratory syncytial virus revealed by cryo-electron tomography. Viruses. 10 (8), (2018).

23. Stobart, C. C. et al. A live RSV vaccine with engineered thermostability is immunogenic in cotton rats despite high attenuation. Nature Communications. 7, 13916 (2016).

24. Hotard, A. L. et al. A stabilized respiratory syncytial virus reverse genetics system amenable to recombinationmediated mutagenesis. Virology. 434 (1), 129-136 (2012).

25. Schindelin, J. et al. Fiji: an open-source platform for biological-image analysis. Nature Methods. 9 (7), 676-682 (2012).

26. Mastronarde, D. N. Automated electron microscope tomography using robust prediction of specimen movements. Journal of Structural Biology. 152 (1), 36-51 (2005).

27. Kremer, J. R., Mastronarde, D. N., Mclntosh, J. R. Computer visualization of three-dimensional image data using IMOD. Journal of Structural Biology. 116 (1), 71-76 (1996).

28. Tang, G. et al. EMAN2: an extensible image processing suite for electron microscopy. Journal of Structural Biology. 157 (1), 38-46 (2007).
29. Yang, J. E., Larson, M. R., Sibert, B. S., Shrum, S., Wright, E. R. CorRelator: Interactive software for realtime high precision cryo-correlative light and electron microscopy. Journal of Structural Biology. e107709, (2021).

30. Ke, Z. et al. Promotion of virus assembly and organization by the measles virus matrix protein. Nature Communications. 9 (1), 1736 (2018).

31. Kim, J., Yang, S., Wildonger, J., Wright, E. A new in situ neuronal model for cryo-ET. Microscopy and Microanalysis. 26 (S2), 130-132 (2020).

32. Bouvette, J. et al. Beam image-shift accelerated data acquisition for near-atomic resolution single-particle cryo-electron tomography. Nature Communications. 12 (1), 1957 (2021).

33. Schorb, M., Haberbosch, I., Hagen, W. J. H., Schwab, Y., Mastronarde, D. N. Software tools for automated transmission electron microscopy. Nature Methods. 16 (6), 471-477 (2019).

34. Weis, F., Hagen, W. J. H., Schorb, M., Mattei, S. Strategies for optimization of cryogenic electron tomography data acquisition. Journal of Visual Experiments. (169), e62383 (2021).

35. Chreifi, G., Chen, S., Jensen, G. J. Rapid tilt-series method for cryo-electron tomography: Characterizing stage behavior during FISE acquisition. Journal of Structural Biology. 213 (2), 107716 (2021).

36. Anderson, D. E., Hinds, M. T. Endothelial cell micropatterning: methods, effects, and applications. Annals of Biomedical Engineering. 39 (9), 2329-2345 (2011). 
37. McWhorter, F. Y., Wang, T., Nguyen, P., Chung, T., Liu, W. F. Modulation of macrophage phenotype by cell shape. Proceedings of the National Academy of Sciences. 110 (43), 17253-17258 (2013).

38. Kleinman, H. K., Luckenbill-Edds, L., Cannon, F. W., Sephel, G. C. Use of extracellular matrix components for cell culture. Analytical Biochemistry. 166 (1), 1-13 (1987).

39. Fassler, F., Zens, B., Hauschild, R., Schur, F. K. M. 3D printed cell culture grid holders for improved cellular specimen preparation in cryo-electron microscopy. Journal of Structural Biology. 212 (3), 107633 (2020).

40. Schellenberger, P. et al. High-precision correlative fluorescence and electron cryo microscopy using two independent alignment markers. Ultramicroscopy. 143, 41-51 (2014). 